\title{
Segregación socioespacial bajo el nuevo modelo de ciudad en América Latina. Características, perspectivas e implicaciones*
}

\author{
Alexandra López Martínez**
}

Recibido: 10 de enero de 2018

Evaluado: 12 de febrero de 2018

Aceptado: 5 de mayo de 2018

\section{ReSUMEN}

El fenómeno de segregación socioespacial ha cambiado su patrón tradicional, principalmente desde finales del siglo $\mathrm{xx}$ de acuerdo a las transformaciones económicas que trajo consigo la globalización en su etapa más desarrollada que es el neoliberalismo. En este artículo se persiguen dos objetivos, por un lado, caracterizar el patrón de segregación socioespacial contemporáneo desde la perspectiva de escala como grado y como valor; y por el otro, avanzar sobre las transformaciones que han producido los agentes y actores sociales a partir de la territorialización de sus acciones en la construcción del espacio urbano. Para el desarrollo de estos objetivos la autora analiza teórica y cualitativamente las características del fenómeno segregativo a escala periubana. Concluye que, a pesar de no darse un proceso de metropolización como en las ciudades globales, la ciudad difusa se va a encontrar mayoritariamente en las ciudades independiente de su preponderancia - si son grandes o no-, y demuestra así que la segregación a pesar de haber cambiado su patrón - geográficamente los grupos sociales se encuentran menos alejados- no ha dejado de ser un fenómeno que está en aumento no por su separación física sino social.

Palabras clave: segregación socioespacial, ciudad intermedia, territorialización.

Artículo de investigación. Hace parte del proyecto doctoral en curso denominada "Segregación residencial, un abordaje territorial multidimensional en el municipio de Ibagué, departamento del Tolima, Colombia. 1990-2017." de la Universidad de Caldas, en el programa de Doctorado en Estudios Territoriales (DET). Bajo la dirección del Doctor Jorge Andrés Rivera Pabón, PhD en Geografía, Planificación Territorial y Gestión Ambiental de la Universidad de Barcelona. Citar como: López, A. (2018). Segregación socioespacial bajo el nuevo modelo de ciudad en América Latina Características, perspectivas e implicaciones. Hallazgos, 15(30), 99-124. DOl: https://doi.org/10.15332/2422409X.4805

** Economista, Estudiante del Doctorado en Estudios Territoriales de la Universidad de Caldas. Becaria del Proyecto Formación de Talento Humano de Alto Nivel de la Universidad del Tolima, Gobernación del Tolima y la Universidad de Ibagué- Integrante del Grupo Interdisciplinario de Estudios sobre el Territorio "Yuma íma" de la Universidad del Tolima. 


\section{Socio-spatial segregation under the new city model in Latin America. Characteristics, perspectives and implications}

\begin{abstract}
The phenomenon of socio-spatial segregation has changed its traditional pattern mainly since the late twentieth century according to the economic transformations brought about the globalization, in its most developed stage, which is neoliberalism. Therefore, in this work two aims are pursued, on the one hand, to characterize the contemporary socio-spatial segregation pattern from the perspective of scale as a degree and as a value, and on the other, to advance on the transformations that agents and actors have produced. from the territorialization of their actions in the construction of urban space. For the development of these aims the author analyzes theoretically and qualitatively the characteristics of the segregative phenomenon on a periuban scale, concluding that although there is no metropolization process as in the global cities, the diffuse city will be found mainly in the cities independent of its preponderance - whether they are large or not-, thus demonstrating that segregation despite having changed its pattern - geographically the social groups are less distant - has not ceased to be a phenomenon that is increasing not because of physical separation but social.
\end{abstract}

Keywords: socio-spatial segregation, intermediate city, territorialization.
Received: january 10, 2018

Evaluated: february 12, 2018

Accepted: may 5, 2018 


\section{Segregação socioespacial sob o novo modelo de cidade na América Latina. Características, perspectivas e implicações}

Recebido: 10 de janeiro de 2018 Avaliado: 12 de fevereiro de 2018

Aceito: 5 de maio de 2018

\section{Resumo}

O fenômeno da segregação socioespacial mudou seu padrão tradicional, principalmente a partir do final do século XX, de acordo com as transformações econômicas trazidas pela globalização em seu estágio mais avançado, o neoliberalismo. Neste artigo, dois objetivos são perseguidos, por um lado, para caracterizar o padrão sócio-espacial de segregação contemporâneo a partir da perspectiva de escala como um grau e como um valor; e, por outro, avançar nas transformações que os agentes e atores sociais produziram a partir da territorialização de suas ações na construção do espaço urbano. Para o desenvolvimento destes objetivos, oa autora analisa teoricamente e qualitativamente as características do fenômeno segregativo em uma escala periubana. Conclui que, apesar de não ter um processo de metropolização como nas cidades globais, a cidade difusa vai encontrar principalmente nas cidades independentes de sua preponderância, -se são grandes ou não-, e mostra que segregação apesar de ter mudado seu padrão - geograficamente, os grupos sociais estão menos distantes - não deixou de ser um fenômeno que está aumentando não por causa de sua separação física, mas social.

Palavras-chave: segregação socioespacial, cidade intermediária, territorialização. 


\section{INTRODUCCIÓN}

Las transformaciones tanto económicas como políticas, las nuevas tecnologías de la información y de la comunicación que se han presentado principalmente desde finales del siglo xx, han sido unos de los factores relevantes junto a la financiarización y la mercantilización del mercado inmobiliario en la transformación y organización del territorio. En este sentido, el estudio de la segregación socioespacial desde la perspectiva de escala como grado y como valor, se convierte en una vía posible para comprender las transformaciones que han producido tanto los agentes y actores sociales en la construcción del espacio urbano como resultado de la territorialización de sus acciones.

No obstante, las dinámicas de la estructura urbana han traído consigo patrones de segregación diferentes desde la época colonial y del periodo de modernización, conocida en un primer momento como la ciudad compacta, comprendida entre el periodo de 1513 y 1820; posteriormente de desarrollo sectorial entre el periodo de 1820 y 1950, respectivamente. Este modelo de diferenciación residencial tradicional se caracterizó por la localización de las actividades comerciales, administrativas y de uso residencial de la clase alta como los aristócratas; y clase media, como los comerciantes, mestizos, artesanos, maestros, entre otros. En el centro histórico, y cerca de él la ubicación de los grupos sociales de bajos ingresos en la periferia, es decir, la posición social en aquella época estaba relacionada por la distancia de acuerdo a la ubicación de la plaza central (Bäbr y Borsdorf, 2005). En esa época colonial (1513-1820) se puede decir entonces que la división social del espacio se evidenciaba de acuerdo a la casta, la raza y la riqueza de los individuos (Aprile y Mosquera, 1984, p. 85). Como muestra de esto, la densidad poblacional es mínima justo en donde se encuentran en su mayoría los equipamientos colectivos, caso contrario en donde la densidad poblacional máxima se encontraba más alejada de ellos.

Con el inicio del desarrollo de las zonas industriales (1820-1950), las cuales se encontraban cerca de las vías ferroviarias o de comunicación, se va cambiando del modelo concéntrico a uno orientado a un crecimiento lineal desde el centro. En la primera mitad del siglo xx, este modelo se caracterizó por la presencia de espacios productivos manufactureros e industriales y áreas residenciales integradas por grupos sociales internamente homogéneos, por sus bajos ingresos cada vez más localizados en la periferia, mientras que la población de clase alta crecía en un sector exclusivo en forma de cono que tenía como vértice en el centro de la ciudad (Espinosa, 1992; Sabatini y Cáceres, 2005).

La suburbanización que se va gestando en la ciudad, principalmente en ciudades latinoamericanas por el desplazamiento de población rural a la ciudad ${ }^{1}$ fue produciendo barrios marginales en la periferia, mientras que la población de clase alta se fue alejando de las áreas tradicionales en las que se concentraban para pasar a ocupar barrios exclusivos. Es decir, se cambia a una expansión celular de los barrios marginales en la periferia - particularmente entre los años 1950 y 1970 - en el que casi que se pierde el contexto espacial inmediato con el área urbana (Bäbr y Borsdorf, 2005, p. 209). Es

1 Para el caso de Colombia, por la guerra civil que se gestaba desde mediados de los años cincuenta del siglo xx. 
así como, por un lado, los pobres acentúan y autoconstruyen nuevos barrios; y por el otro, los ricos se van alejando de la zona central de la ciudad ocupando ya no las casonas con grandes solares, si no comprando casas en conjuntos cerrados y condominios hacia la periferia. Es a partir de la década de los años noventa en donde la estructura de las ciudades cambió de una polarizada a una fragmentada, como consecuencia de los procesos de globalización y de transformación económica en donde la distancia espacial entre grupos poblaciones ricos y pobres disminuyó, pero la segregación aumentó y es en este periodo de estudio en donde se centra el análisis de este trabajo sobre la segregación socioespacial entre 1990 y 2015 a escala periubana.

Este artículo está compuesto de tres partes: en primer lugar, se presenta una caracterización a partir de los años noventa del siglo $x x$ de la segregación socioespacial. En segundo lugar, se indican cuáles son los actores y agentes sociales que, a través de sus acciones, territorializan la ciudad difusa, se utiliza como caso de estudio al municipio de Ibagué, Tolima, Colombia. Tercero, se expone la importancia de emprender el estudio de la segregación desde un énfasis transdisciplinar en razón a las múltiples dimensiones que incorpora su naturaleza compleja: económica, social, política y cultural. Por último, se describen las conclusiones y consideraciones finales.

\section{SEGREGACIÓN SOCIOESPACIAL DESDE LAS ESCALAS DE GRADO $Y$ DE VALOR}

A finales del siglo $x x$, bajo el modo de producción capitalista en su etapa más destacada que es el neoliberalismo, ${ }^{2}$ juegan un papel importante la financiarización, el papel del Estado como promotor desde la demanda del mercado inmobiliario, los agentes privados como el sistema bancario, los constructores y urbanizadores privados, los propietarios de la tierra y de los medios de producción en la mercantilización de la vivienda, la cual se refleja en la transformación de los estilos de vida de los grupos poblacionales. De manera que la ciudad fragmentada de la época cambia la escala en la que se venía presentando la segregación socioespacial de una escala grande a una pequeña, promueve el sesgo y la posibilidad de acceso a la vivienda de acuerdo al capital que poseen los grupos poblacionales objetivo, de modo que se produce una ciudad formal o planificada - por la fuerzas del mercado- y una ciudad informal o espontánea, propia de los espacios de reexistencia y reconstrucción de la vida de los desplazados por la violencia, la crisis rural, entre otros. (Rivera, 2013).

En consecuencia, la producción social del territorio ha tenido transformaciones en relación a los ciclos de la economía especialmente en la lógica de localización en concordancia al capital que poseen los actores sociales, de esta manera:

[...] el capital, [...], aparece como organizador y estructurador territorial preponderante, basándose en los múltiples recursos y ventajas competitivas

2 El neoliberalismo es la etapa de mercado más desarrollada del modo de producción capitalista, que se expresa además, en nuevas lógicas de planeación y ordenamiento territorial, que dispone de los recursos que están en el territorio para atender las diferentes lógicas y actividades del mercado independiente de quien se beneficie bajo fines específicos, por lo tanto no es un modelo que promueva la mitigación de la segregación en la ciudad (Torres et al., 2009). 
de cada porción del territorio metropolitano, extrayendo las plusvalías más cuantiosas precisamente de las singularidades y especificidades que hacen de cada fragmento el lugar óptimo para cada tipo de producción. (Ciccolella y Vecslir, 2010, p. 2).

La posesión del capital de estos actores sociales puede ser obtenida a partir de una renta monopolística dependiendo de si son los dueños de la mercancía o si son los propietarios del terreno o el recurso propiamente (Harvey y Smith, 2005). Pero esta renta tiene dos contradicciones, una es que el requisito de comercialidad indica que ningún producto puede ser más excepcional que otro, por lo tanto, al convertirse un bien que se produce en masa, pierde su carácter excepcional, que fue lo que le sucedió al modelo Fordista; y la otra, es la eliminación de las empresas más débiles del mercado con el fin de crear monopolio u oligopolio, para que la competencia sea más fuerte y cree la centralización del capital que fue lo que sucedió en el modelo Posfordista (Harvey, 2013).

Entonces, de acuerdo a la transición del periodo fordista al posfordista - entre 1970 y 1980 - en el que se deslocalizan y reubican los espacios industriales en áreas extraurbanas, se da el proceso de metropolización cuando la ciudad pasa de crecer de manera continua y concentrada para hacerlo de manera fragmentaria (Janoshcka, 2002, p. 16). Por ello se entiende como un proceso que tiene sus raíces desde el siglo xx con la desindustrialización, precedida por la evolución del transporte público y los medios de comunicación.

Es precedida porque da su punto álgido con el modelo Fordista que producía autos en cadena, el cual transformó las técnicas de producción y las formas de vida. La primera porque moderniza sus fábricas para producir en masa; y la segunda, porque esa producción debe ser también consumida en masa, de ahí que se ajustaran salarios no por su valor agregado al trabajo, sino con el fin que, a través de ellos, se absorbiera esa producción y los trabajadores pasaran a cumplir el papel disciplinado donde se obedeció a las funciones repetitivas, donde su conocimiento pasa a un segundo plano convirtiéndose en un "obrero masa" (Fernández, 1996, p. 37). Este modelo se manifiesta en el territorio en la "gran área metropolitana, con una especialización social y funcional del espacio muy acusada" (Fernández, 1996, p. 37) “este nuevo tipo de crecimiento urbano [...] induce la creación de nuevos niveles de gobierno intermedios entre lo local [...] y lo central" (Fernández, 1996, p. 38).

Con los cambios en los sistemas industriales desde los años setenta, se buscó que los costos salariales disminuyeran a través de mano de obra no calificada, promoviendo jornadas laborales extensas con bajos salarios, estrategia acompañada de poca vigilancia de las normas laborales que propendieran por regularizar las prestaciones de ley de los empleados. Este cambio estuvo acompañado del desplazamiento de las empresas industriales desde el centro a la periferia de la ciudad con el fin de aumentar su plusvalía, se cambiaron las zonas industriales por las residenciales, y estuvo asistido por la especulación inmobiliaria.

A partir de los años noventa, se convierte al suelo aún más en una mercancía, suceso en el cual el Estado sigue teniendo un rol de regulador - a través de normas y leyes-, pero interviene con un mayor énfasis en 
el mercado inmobiliario (Janoshcka, 2002; Janoshcka y Glasze, 2003; Moura, 2003; Sabatini y Cáceres, 2005; Sabatini, Cáceres, y Cerda, 2001; Torres et al., 2009 y Valdés, 2007). No obstante la entrada en vigor del neoliberalismo, se conservan dos características de la distribución socioespacial, que son: la tendencia sectorial lineal y el crecimiento celular; pero de manera más palpable, es decir, ya no están en localizaciones extremas de centro-periferia por grandes zonas tanto residencial e industrial (Bäbr y Borsdorf, 2005). A partir de ésta época las zonas se van haciendo más pequeñas y localizadas por toda la ciudad mezclándose espacios entre sí, es decir, barrios marginales cerca de urbanizaciones de lujo.

Lo anterior refuerza la división socioespacial que se sigue conservando por características económicas y culturales, así como la densidad poblacional que continúa con la caracterización de la clase a la que pertenecen los grupos poblacionales. Sin embargo, esto no significa que también se dé una mezcla social por haberse acortado la distancia geográfica entre ellos, lo que sucede es que los ricos habitan conjuntos residenciales cerrados, con seguridad privada, entre otros servicios que les permita diferenciarse de los demás, denotando exclusividad frente a los otros, pero esta exclusividad se diferencia de los conjuntos cerrados de los pobres principalmente por los servicios y equipamientos privados con los que cuentan. De manera paralela, tanto las zonas industriales como de comercio se van ubicando en diferentes zonas de la ciudad perdiendo la característica de centro dominante de ambas zonas que era una particularidad de la ciudad colonial, sectorial y polarizada (Bäbr y Borsdorf, 2005). De este modo, la nueva expresión de la segregación cambia a través de la concentración del capital inmobiliario, la promoción de la construcción de conjuntos cerrados, la innovación de producto, entre otros. De tal manera que la forma de cono como área concentrada de las élites pasa a estar dispersa por efectos de la concentración del capital y la liberalización de los mercados de suelo (Ríos, 2010; Sabatini y Cáceres, 2005).

Por lo anterior, se puede decir que la posición social ya no determina la posición geográfica - distancia - pues se desarrollaron nuevas lógicas de separación y fronteras urbanas, en el que las ciudades pasan de ser ortogonales a tener un modelo fractal. Entre las nuevas lógicas de separación se encuentra la de consumo, el cual da un reconocimiento frente a los "otros" de acuerdo a lo que puedan adquirir en relación al capital que poseen. De tal manera, la población se distribuye, en términos de gradiente, lo que sería "un fenómeno que toca a una gran parte del territorio y que acentúa las fronteras entre los diferentes barrios, incluso entre islotes, yendo al encuentro de la representación clásica de la pobreza" (Prévôt, 2000, p. 417). Los grupos poblacionales que se van segregando a través, de las "fronteras", son los que poseen el capital necesario y suficiente para crear espacios privilegiados, bien sea por razones económicas, políticas o culturales (Cortés, 2010; Hiernaux, 1999), de ahí que los "otros" serán la población que represente la precariedad de la condición humana, es decir, "son los portadores de las diferencias que nos provocan más miedos y contra los cuales nos trazamos las fronteras y levantamos los muros" (Cortés, 2010, p. 119).

Para la época colonial, en la que eran claras las delimitaciones entre el centro y la 
periferia, se pasa de un época en la que las características como la densidad poblacional es baja pero su consumo por el mercado del suelo es creciente, a una expansión progresiva de la periferia en relación al centro -indistinta de si es exclusiva de grupos poblacionales de bajos ingresos o no-, por lo que la concentración poblacional disminuye pero aumenta la falta de proximidad - distancia - entre los grupos poblacionales diferentes, conllevando a una fragmentación del territorio (Cuervo, 2010; De Mattos, 2001, 2012). Ésta se refleja en una suburbanización - periferias metropolitanas en promedio densas - y periurbanización -en las dinámicas metropolitanas de los antiguos núcleos rurales - en el que se plasma una forma urbana de nuevas tendencias de segregación socioespacial que promueven una distribución desigual de oportunidades y de beneficios en la población, muy al contrario de pensar que la propensión sería disminuir la segregación, por el contrario, la tendencia dominante es el aumento de las desigualdades intrametropolitanas (Cuervo, 2010).

Lo que pasó en realidad es que al haber desplazamientos poblacionales intraurbanos desde las áreas más densas y pobladas de los sistemas urbanos hacia zonas de poblamiento más difuso, se provocó una disminución de la densidad en la zona centro como primera medida. Pero como se estaba en la dinámica de la oferta y demanda del mercado del suelo y la vivienda, sólo aquellas personas que no tenían características sociales como educación, o económicas como un salario superior a la media poblacional, se vieron afectados de manera distinta que al resto, es decir, los primeros se movieron a aquellas zonas de alta renta mientras que los demás quedaron relegados en el centro, generándose nuevos patrones segregativos (Nel.lo, 1998).

De acuerdo a lo anterior, se puede decir que se presentan dos tipos de injusticias a causa de los procesos de globalización y transformación económica. Por un lado, está la mala redistribución de los grupos poblacionales en el espacio urbano, generado a raíz de la incapacidad de las estructuras económicas para brindar los ingresos necesarios para que la población no se separe según características socioeconómicas como el salario o la educación, que los hagan diferenciarse por grupos que internamente sean homogéneos pero entre ellos dispares. Por el otro, el reconocimiento fallido o desigualdad del estatus (Fraser, 2008) el cual se da cuando los desposeídos social y económicamente son excluidos y relegados a las zonas no solo con menores servicios y equipamientos sino también de baja calidad, contexto que contribuye además a que este grupo poblacional no alcance el reconocimiento y legitimación de su cultura "así, se ha estigmatizado el rol de las expresiones culturales de quienes se dice, son indignos y no merecedores de habitar la ciudad. Al parecer, la ciudad moderna e industrializada facilitó todo este fenómeno" (Lacarrieu, 2007, p. 50).

A este panorama se suma la representación fallida, la cual se evidencia cuando "las reivindicaciones de la población pobre del mundo se relegan a ámbitos políticos internos de Estados débiles o fallidos y se le impide oponerse a las fuentes externas de su desposeimiento" (Fraser, 2008, p. 22). Esta representación se deriva de una globalización que es excluyente. En efecto, en el contexto de las actuales ciudades globales (Sassen, 2015) se establecen empresas 
e instituciones transnacionales, de comunicación, entre otras; que en su conjunto contribuyen a una dualización sociolaboral desde la tercerización de la economía. En esta dinámica aumenta el estrato de los directivos de las empresas y a su vez aumenta la absorción de mano de obra no calificada con precarios salarios, deteriorando así el estrato de este grupo poblacional. Por tanto, este panorama sostiene a la globalización (Méndez, 2001), situación que sucede en sociedades políticas delimitadas como las latinoamericanas.

\section{TERritorialización DE LAS ACCIONES Y LA CIUDAD DIFUSA}

Las políticas públicas territorializadas van cambiando, con el paso del tiempo, los usos de los espacios, las cuales se apoyan en criterios tanto políticos como económicos que promueven en el espacio una valoración distinta que diferencia la población de acuerdo al tipo de residencia promovida principalmente por el sector privado (Ábramo, 2003; De Mattos, 2002; Harvey, 1977; Janoshcka, 2002 y Torres et al., 2009). En efecto, la territorialización, desde lo planteado por la Antropóloga Beatriz Nates, es "la estrategia que se utiliza, y el efecto que causa el delimitar un territorio" (Nates, 2011, p. 212). En el contexto de una economía de mercado globalizada que debe hablar un mismo lenguaje con el fin de minimizar las diferencias, se puede decir que en realidad esto no sucede. Lo que pasa en estas condiciones es que la hiperconexión desarrollada bajo la globalización ha hecho que la vecindad geográfica se desdibuje y se potencie cada vez más el desarrollo ligado a sus conexiones dadas a distancia, por lo que la fragmentación social, política, económica y territorial es el producto de considerar la localización geográfica de las funciones y las actividades globales como el todo. Estos procesos se dan en la base de un territorio que es un bien público del cual los actores sociales colectivos pueden resistirse y reforzar sus identidades locales frente a las globales, teniendo en cuenta que en sus territorios existen recursos potenciales específicos que son inmóviles y en una sociedad y una economía globalizada postfordista son vistos como productos con una especificidad local, se podrán transformar en una ventaja competitiva y no comparativa (Dematteis y Governa, 2005, pp. 33-35).

De modo que los procesos que han contribuido a la transformación de la ciudad en una urbanización policéntrica (Vega-Centeno, 2017) evidencian de manera importante que a partir de la década de los años setenta "los cambios en los sistemas industriales, relacionados en parte con la crisis de 1973 y con los procesos de reestructuración industrial subsiguientes; y [...] el desarrollo de las nuevas tecnologías de la información y la comunicación" (Capel, 2002, p. 203). Las características principales de la ciudad difusa se basan en cambios del mercado de trabajo, el desplazamiento de industrias y la tercerización del centro de la ciudad.

Por consiguiente, en cuanto al mercado de trabajo con los cambios en los sistemas industriales desde 1970, se buscó que la mano de obra fuera uno de los factores con los que se bajaran los costos de la producción con el fin de disminuir los precios de los productos, situación que se logró con extensas jornadas laborales a bajos salarios, costos salariales que se disminuyeron a causa de una casi o nula ausencia de normas que 
regularizaran las prestaciones de ley de los empleados, esto permitió la alta presencia de mano de obra barata.

A partir de esas condiciones la estabilidad laboral se ha ido difuminando, por lo que es más frecuente el cambio del puesto de trabajo y la precarización del empleo. Esto acompañado del desplazamiento de las empresas industriales desde el centro a la periferia de la ciudad con el fin de aumentar su plusvalía y cambiando las zonas industriales por las residenciales, asistido por la especulación inmobiliaria en las zonas que dejan atrás las empresas industriales y la especulación del precio del suelo en zonas de la periferia donde inicialmente el valor de uso del suelo es económico, pero pueden llegar a venderlo más como un uso de cambio a través de estrategias de marketing con la promoción de venta de "vivir en el campo sin alejarse de la ciudad". Es así como en los tres últimos decenios "una localización cada vez más exterior de los empleos, un mantenimiento de otros en situación central pero con desplazamiento de la mano de obra a la periferia, y una separación creciente de la vivienda y el trabajo" (Capel, 2002, p. 206), es una situación que es favorable para los empleadores y no para los empleados.

Lo que hay detrás de estos cambios en los sistemas industriales es la ventaja de localización en concordancia con las economías de aglomeración a nivel urbano según los espacios económicos y las escalas geográficas que son actualmente cada vez más grandes (Sassen, 2007). Como consecuencia de los cambios anteriores, se crean nuevos centros - policentro - en la periferia con oficinas y a su vez con actividades terciarias comerciales, centros de ocio, parques científicos, distritos de manufacturas, entre otros; que se harán notar dependiendo de qué tan grande sea el área metropolitana sin que se afecte la jerarquía de la centralidad de la ciudad, dejando de cierta manera una autonomía a la periferia con respecto a la ciudad principal. No obstante, los espacios que se creen públicos pueden tener carácter de privados por el tipo de construcciones que se hacen dirigidos a una población específica -de ingresos altos - , por lo tanto, se evidenciarán flujos tradicionales entre centro y periferia $y$, de forma inversa, se complementa en el espacio periurbano, pues es importante tener en cuenta que el centro-periferia contemporáneo es dinámico aunque desigual.

De manera paralela, con la dinámica del mercado de oferta y demanda que generan presión en la oferta, el ciudadano se convierte en un consumidor de bienes y servicios, consumo reforzado por el mercado inmobiliario (Bernardes da Silva y Castillo, 2007), es así como "a partir de estos nuevos artefactos arquitectónicos y urbanos comienza a organizarse una nueva manera de segregar y discriminar grupos y actividades sociales en el espacio metropolitano, emergiendo una nueva dinámica inmobiliaria que intensifica la privatización de la ciudad y que puede constituirse en un modelo" (Pereira, 2004, p. 2).

Estas acciones son producidas por el actuar de los agentes sociales, como los promotores inmobiliarios - empresas constructoras y de financiamiento, técnicos y profesionales al servicio de la promoción, venta, construcción y comercialización inmobiliaria-, los propietarios de la tierra, el Estado y los actores 
sociales como los grupos sociales excluidos y los grupos sociales integrados (Corrêa, 1989). El papel del promotor inmobiliario es crucial en el mercado del suelo, este agente es el intermediario entre otros agentes para llevarlo a cabo; los promotores se encargan de realizar varias funciones, entre ellas las incorporaciones necesarias a la transformación del predio que luego será construido, después la comercialización y construcción del mismo, la gestión de financiamiento para la compra y para emprender las construcciones de bienes inmuebles, entre otras funciones que culminan con la comercialización de la residencia que es donde capital/producto pasaría a ser capital/dinero.

De lo anterior cabe decir que el incentivo inicial para un promotor inmobiliario es solucionar el déficit habitacional de la población de altos ingresos por la alta renta que le generan. El grupo que le sigue es la población de ingresos medios a los cuales les ofrece desarrollos inmobiliarios con algún grado de diferenciación que le siga permitiendo obtener rentas altas del suelo. Por último, están los demandantes potenciales pero de ingresos bajos, en los que tiene opción de mercado a través de subsidios a la vivienda otorgados por el Estado.

El Estado no solo es regulador de la organización espacial, es propietario de tierras, es demandante de espacio y promotor inmobiliario - mediante subsidios para planes de vivienda social- - . De esta manera, el Estado es el responsable de la organización del espacio y de la asignación adecuada de los equipamientos colectivos ya que, si esta asignación se hace de manera desigual en la ciudad hará que unas zonas se valoricen diferencialmente promoviéndose desde el
Estado la segregación residencial (Corrêa, 1989, pp. 24-25).

Por su parte, los propietarios de la tierra actúan en pro de obtener una mayor renta por sus propiedades con el mercado residencial o comercial. Su actuar se basa en la ubicación estratégica de los terrenos, de esto depende los demandantes potenciales, si la posición geográfica es buena gestionará con el Estado la adecuación de infraestructura urbana y la obtención de permisos para construcción de complejos habitacionales y además buscaran negociar con las entidades bancarias para obtener préstamos que les permitan emprender la construcción inmobiliaria. En cambio, si no lo es, entonces el incentivo a la obtención de renta será menor y lo que hará será lotear y esperar a ganar alguna renta sobre el terreno, aunque este tipo de lotes suelen ser habitados con viviendas de autoconstrucción en las que se presentan condiciones habitacionales por lo regular precarias.

Estos grupos sociales excluidos además de la autoconstrucción de vivienda tienen la opción de adquirir vivienda a través de subsidios que ofrezca el Estado. Cualquiera de las dos formas de obtener vivienda, por lo regular, estará localizada en la periferia urbana, donde el valor del suelo es bajo, zonas en donde la movilidad social se hace menos probable, logran mantenerse en sus viviendas y consolidan una identidad colectiva del lugar que habitan. Por lo tanto, las acciones colectivas buscarán en el Estado la legalización de sus barrios - en el caso de la autoconstrucción en zonas ilegales - que se les suministre los servicios públicos básicos y se les dé los equipamientos públicos necesarios para vivir en armonía. 
Por su parte, los grupos sociales integrados, como los denomina Roberto Correa (1989), son aquellos que pertenecen a la población de clase alta y media que promueve una posible autosegregación, consiguen tener en un solo lugar los bienes y servicios suficientes - como seguridad privada, zonas de esparcimiento, administración privada, entre otros - que les permita poca interacción con personas de clases opuestas a las de ellos. Este tipo de autoesegregación no es del todo voluntaria, las fronteras visibles como los muros, son mecanismos de protección frente a un entorno de inseguridad (Schteingart, 2001). Este grupo de población tiene la ventaja de pertenecer a altos cargos de la política y de entidades del Estado lo que les permite generar presión para que haya prioridad en la construcción de equipamientos urbanos públicos, consiguiendo de manera paralela la valorización de sus predios.

\section{Estudio de CASO. IbAgué, Tolima (Colombia)}

Ibagué es una ciudad intermedia y es la capital del departamento del Tolima, ubicada en su centro, el cual se encuentra en el centro de Colombia, con una población aproximada de 553.524 de habitantes en el 2015 de acuerdo al Informe de Ibagué Cómo Vamos (2015). La ciudad cuenta con una división político administrativa, la componen trece comunas que se distribuyen en cuatro zonas: zona noroccidental -comunas 1, 2, 3 y 4 -, zona nororiental - comunas 6, 7 y $8-$, zona suroriental - comuna 5 y $9-$ y la zona suroccidental - comunas 10, 11, 12 y 13- (ver figura 1). Entre las comunas más destacables se encuentra la comuna 1, que es donde se ubica la zona fundacional de la ciudad y representa la mayor participación del uso espacial y de comercio; y la comuna 5 , en donde se ha establecido un nuevo centro con centros comerciales la cual le ha dado una alta valorización a los barrios aledaños.

La reestructuración del desarrollo en el municipio de Ibagué a partir de la década de los años setenta, transformó la configuración del espacio y la fragmentación de la población. Ésta se fue localizando en la ciudad de acuerdo a sus condiciones socioeconómicas, de tal manera que la ciudad fue tendiendo a una expansión celular tanto de las viviendas como de la industria y el comercio. Situación que es consecuente con la menor migración que se presentaba para la época en relación a los años anteriores, esto a causa del estancamiento de la producción rural provocado años atrás por la violencia bipartidista, por lo que era menester seguir fortaleciendo la infraestructura pública por parte del Estado, la cual favoreció de forma especial a la población de clase media-alta, se generó así una valorización del suelo urbano de los lugares ocupados por ellos. En efecto, las vías relevantes de la ciudad - como la Carrera Quinta y la Avenida Ambalá, ver figura $2-$ constituyeron una característica primordial para la expansión urbana que se dio luego. A esta situación se suma la poca intervención estatal para dar solución habitacional efectiva y que se contrarrestó con la autoconstrucción de vivienda seguida de la intervención de firmas privadas.

Para esa misma época, debido al poco fortalecimiento del sector secundario, las empresas agroindustriales no salían del alcance local y regional por lo que la empleabilidad no tuvo un aumento significativo en este 


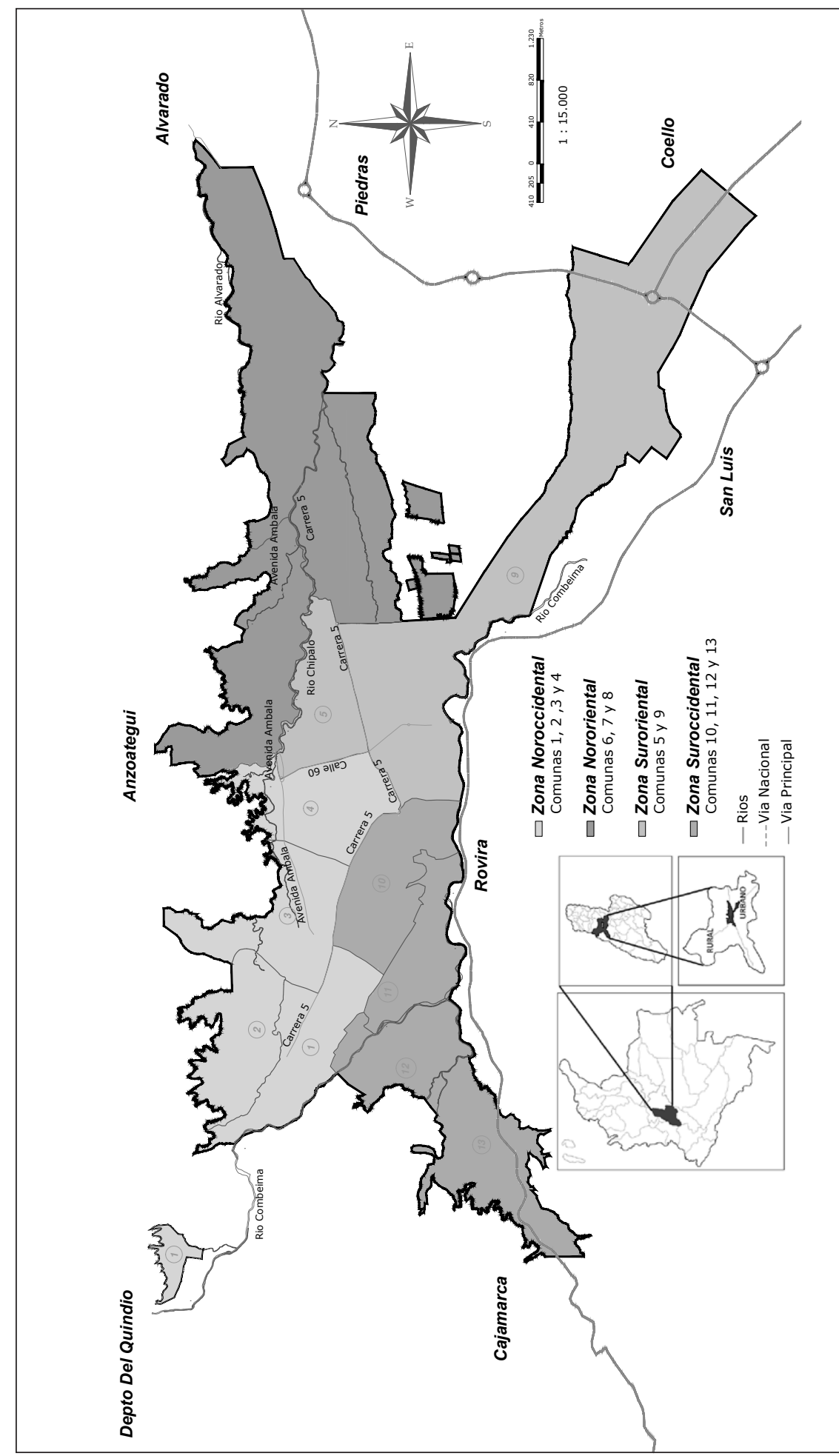

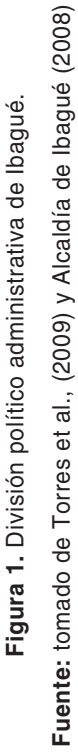


periodo. Por su parte, la actividad edificadora acogió la tendencia de construcción de viviendas en apartamentos y no de casas en serie como sucedía anteriormente. Así mismo, esta década es el producto de la implementación de modelos como el de la industrialización vía sustitución de importaciones (Espinosa, 1992). Finalizando la década de los años ochenta, a causa de la erupción volcánica en Armero, ${ }^{3}$ la fase de industrialización se consolida, en especial por la exención de impuestos a los empresarios para activar la economía de la ciudad (Espinosa, 1992 y González, 2006). Las soluciones habitacionales de la población damnificada por la avalancha se dieron en la zona nororiental de Ibagué, manteniendo la tendencia de la expansión urbana que se venía dando desde 1985 hasta la década de los años noventa (Espinosa, 1992, p. 167). Paralelamente fueron surgiendo viviendas autoconstruidas principalmente alrededor del Río Chipalo, Salado en la comuna 7, Ambalá en la comuna 6 y Picaleña en la comuna 7 (ver figura 1) (López, 2017).

Posteriormente, desde la década de los años noventa, se adopta principalmente en Colombia el modelo neoliberal mediante el cual se transforma la economía a través de la globalización y con él cambia el mercado inmobiliario. A nivel social, la globalización económica-cultural dio paso a cambios en la forma de consumo de la vivienda, lo que tiene una incidencia directa en la definición del lugar de residencia. Entonces, se puede decir que con la aparición del neoliberalismo y las medidas de privatización -asociados al desarrollo urbano: inmobiliario y

3 Fue la catástrofe natural que se dio en el año de 1985 con la erupción del Volcán Nevado del Ruiz, tuvo como consecuencia la desaparición del municipio de Armero (Espinosa, 1992) de construcción-, se consolidaron barrios pobres y se autoconstruyeron otros nuevos, aumentó la presencia y la calidad de conjuntos cerrados acrecentando así la brecha social y el incremento de la expansión del espacio urbano.

Particularmente para finales del siglo xx la ciudad presenta altos índices de desempleo como consecuencia de la crisis de 1998-1999, esto afectó el crecimiento de la industria local que había sido promovida por el gobierno nacional para reactivar la economía por la avalancha de Armero, en consecuencia, esta situación se tradujo en una tasa de desempleo que en promedio, desde el 2001 hasta el 2014, ha sido de 18,7 \%, de acuerdo a Ayala (2014). Por añadidura, la solución de vivienda para la población de clase baja ha sido coyuntural y no estructural, es decir, el gobierno municipal ha legalizado aquellos barrios precarios que por lo regular están ubicados en la periferia de la ciudad, donde el acceso de las vías y la infraestructura física no es el adecuado y donde los problemas sociales como hacinamiento, delincuencia común, daño ambiental, entre otros, persisten o se agudizan. En contraste, estas soluciones de vivienda difieren con las de la población de estratos medios y altos, gracias al marketing de los promotores inmobiliarios quienes ofertan viviendas con la mejor ubicación y con espacios más amplios para vivir en conjuntos cerrados, espacios que difieren de las Viviendas de Interés Social (VIS) con áreas mínimas de 22,5 metros cuadrados, en lotes de 50 metros cuadrados (Vargas, Jiménez, Grindlay y Torres, 2010, p. 80).

Para ejemplificar la dinámica de la liberalización del mercado del suelo, en el caso de Ibagué, se puede observar en la figura 2 la dinámica que tiene una ciudad intermedia 


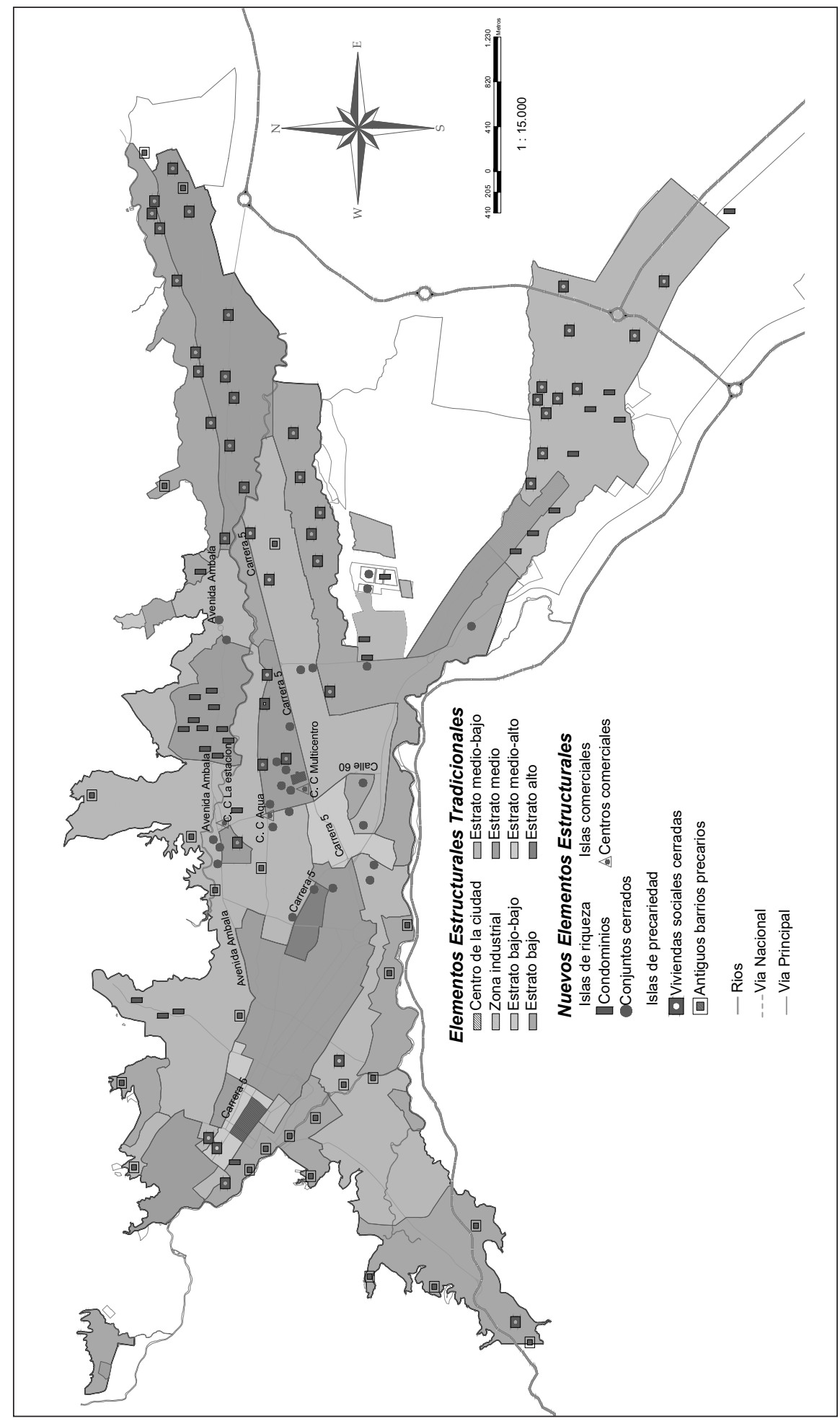

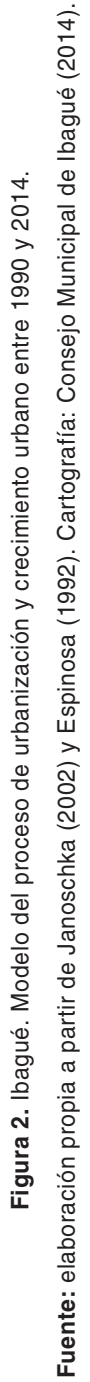


con respecto al nuevo modelo de ciudad latinoamericano (Janoshcka, 2002). En el mapa se presentan los elementos estructurales tradicionales con información del año noventa (Espinosa, 1992) y los nuevos estructurales con información del 2014, este último lo conforman las islas de precariedad, de riqueza y de comercio. De la primera hacen parte los conjuntos y condominios cerrados de vivienda, de la segunda hacen parte los barrios informales autoconstruidos, las VIS y las viviendas de interés prioritario (VIP); y de la tercera, los centros comerciales (Janoshcka, 2002). Este modelo ha transformado al modelo de ciudad tradicional - colonial y sectorial - por lo que los nuevos desarrollos inmobiliarios contribuyen al cambio de patrón de la segregación en el que la polarización disminuye pero la segregación aumenta, a pesar de la cercanía entre grupos poblacionales socioeconómicamente diferentes entre ellos (Janoshcka, 2002 y Sabatini et al., 2001).

En cuanto a los elementos estructurales tradicionales, se puede observar - ver figura 2- que en el centro de la ciudad se encuentra un modelo de crecimiento lineal orientado desde el centro, conformado por la zona administrativa, comercial, seguida del sector residencial de clase media y alta, que a la postre se encuentra con la zona de clase baja. Ubicados para la época en el costado sur del centro en el que se encuentran viviendas de autoconstrucción tradicionales, en contraste, las soluciones de vivienda para la clase social baja se construyeron hacia el nororiente - Jardín, Atolsure, Comuneros, Pedregal- y centroriente - Jordán II, VI VII - de la ciudad y hacia la zona suroriental - Proarroz, Confecciones Carolina - y noroccidental - Planta de sacrificio - con la zona industrial en suelo urbano y de expansión (ver figura 3).

En relación a los nuevos elementos estructurales aparece la ciudad de islas, como la denomina (Janoshcka, 2002), en este sentido las islas residenciales de riqueza para el caso de Ibagué cuenta con el condominio Las Victorias y se ubica en la zona de expansión de la ciudad hacia el suroriente, como conjuntos cerrados de apartamentos y casas de lujo están El Portal del Campestre (ver figura 3 y 4) Filadelfia, Madeira campestre, entre otros. 


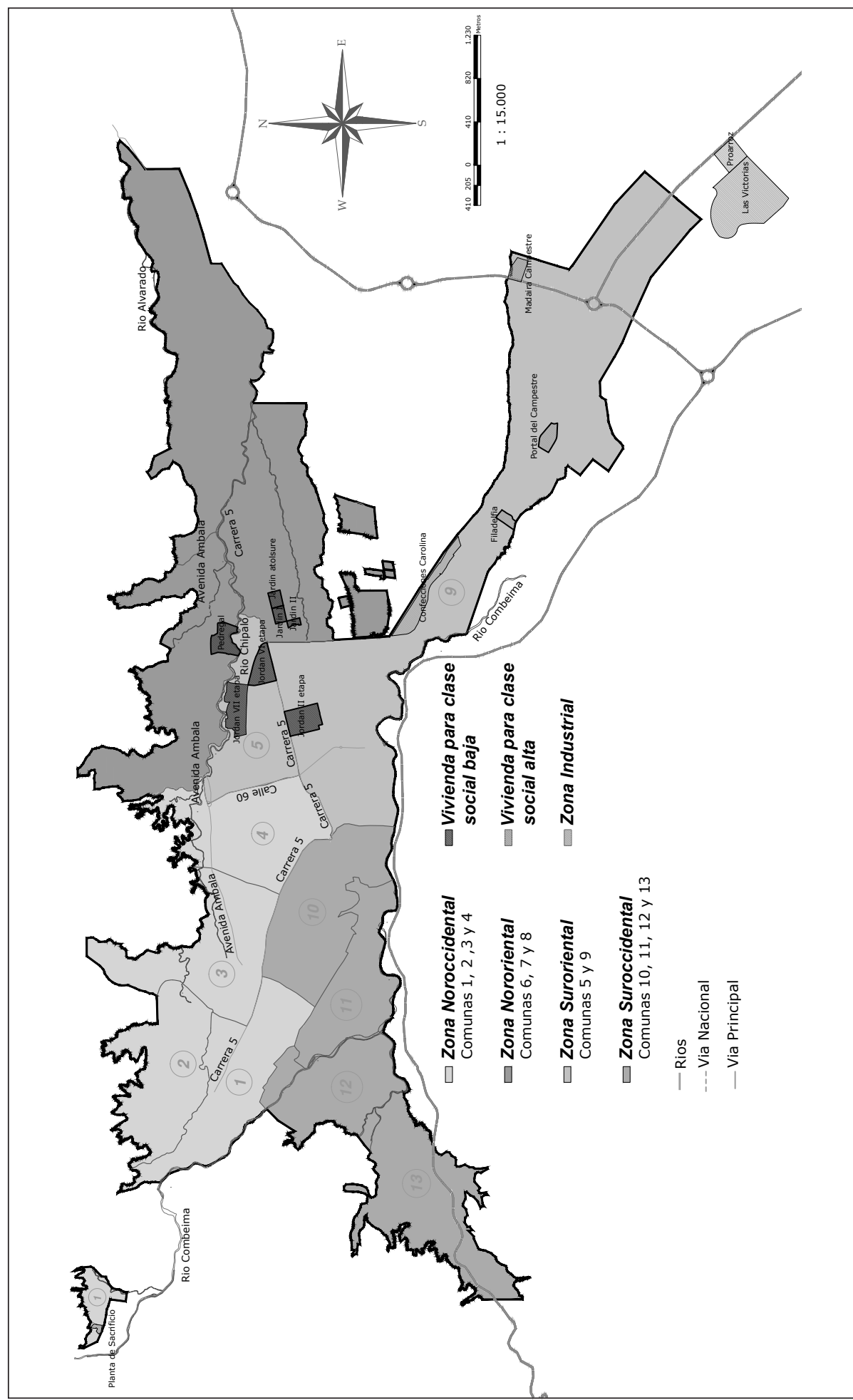

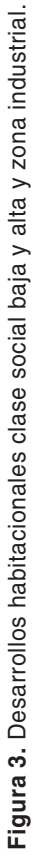



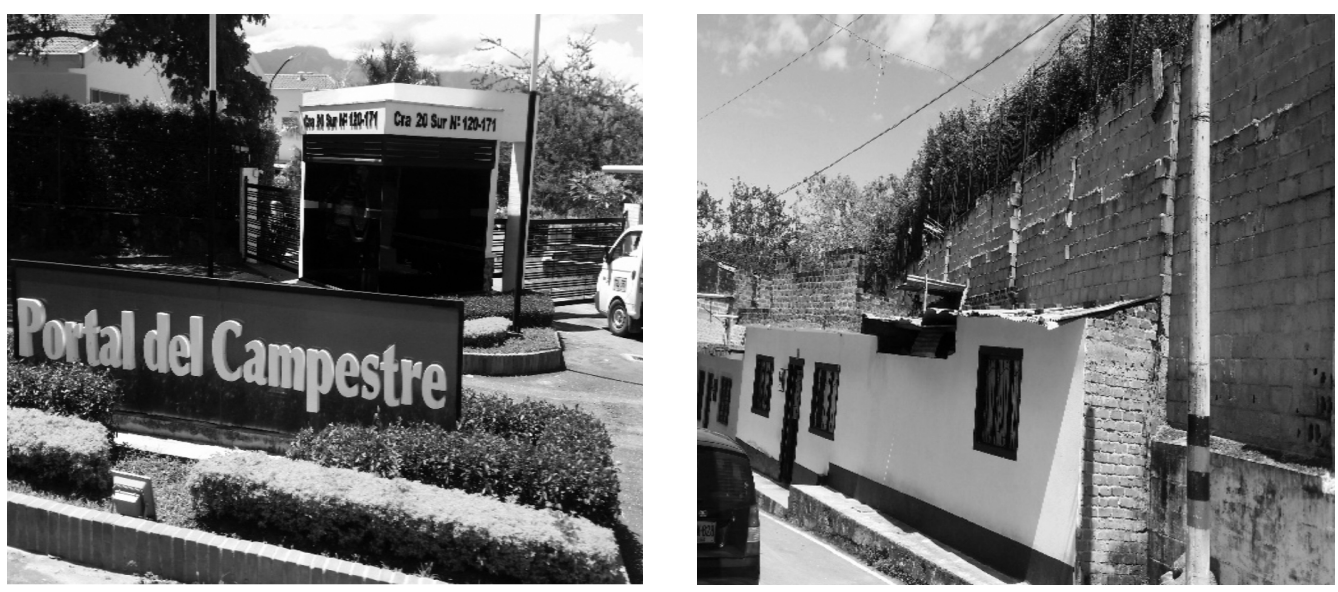

Figura 4. Comuna 9, Ibagué. Zona urbana. Conjuntos cerrados de élite —Portal del campestre, izquierdavs. casas población ingresos bajos -Bello Horizonte, derecha-.

Fuente: elaboración propia, mayo 2017.

En contraste, en las islas de precariedad se cuenta con cerca de 65 antiguos barrios precarios con una ubicación más pronunciada hacia la periferia y en las riberas de los ríos Combeima - suroccidente-, Chipalo y Alvarado - nororiente - con una mayor localización en las comunas 2, 7 y 13 las cuales son las comunas con presencia entre el $60 \%$

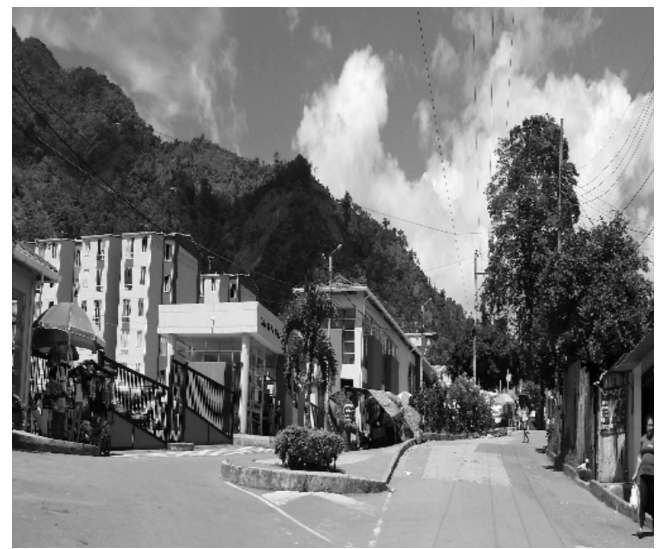

y $90 \%$ de población de estratos bajos de la ciudad (ver figura 5).

No obstante, la construcción de conjuntos cerrados de vivienda de interés social se han ubicado cerca de algunos barrios precarios tradicionales, pero ello no significó que dichos barrios desaparecieran (ver figura 6).

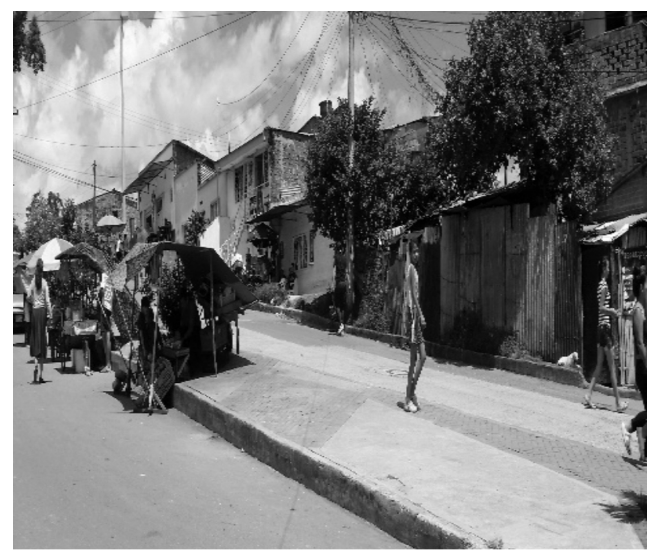

Figura 6. Comuna 13, Ibagué. Zona urbana. Conjuntos cerrados de VIS -EI Tejar, izquierdavs casas tradicionales precarizadas.

Fuente: elaboración propia, mayo 2017 


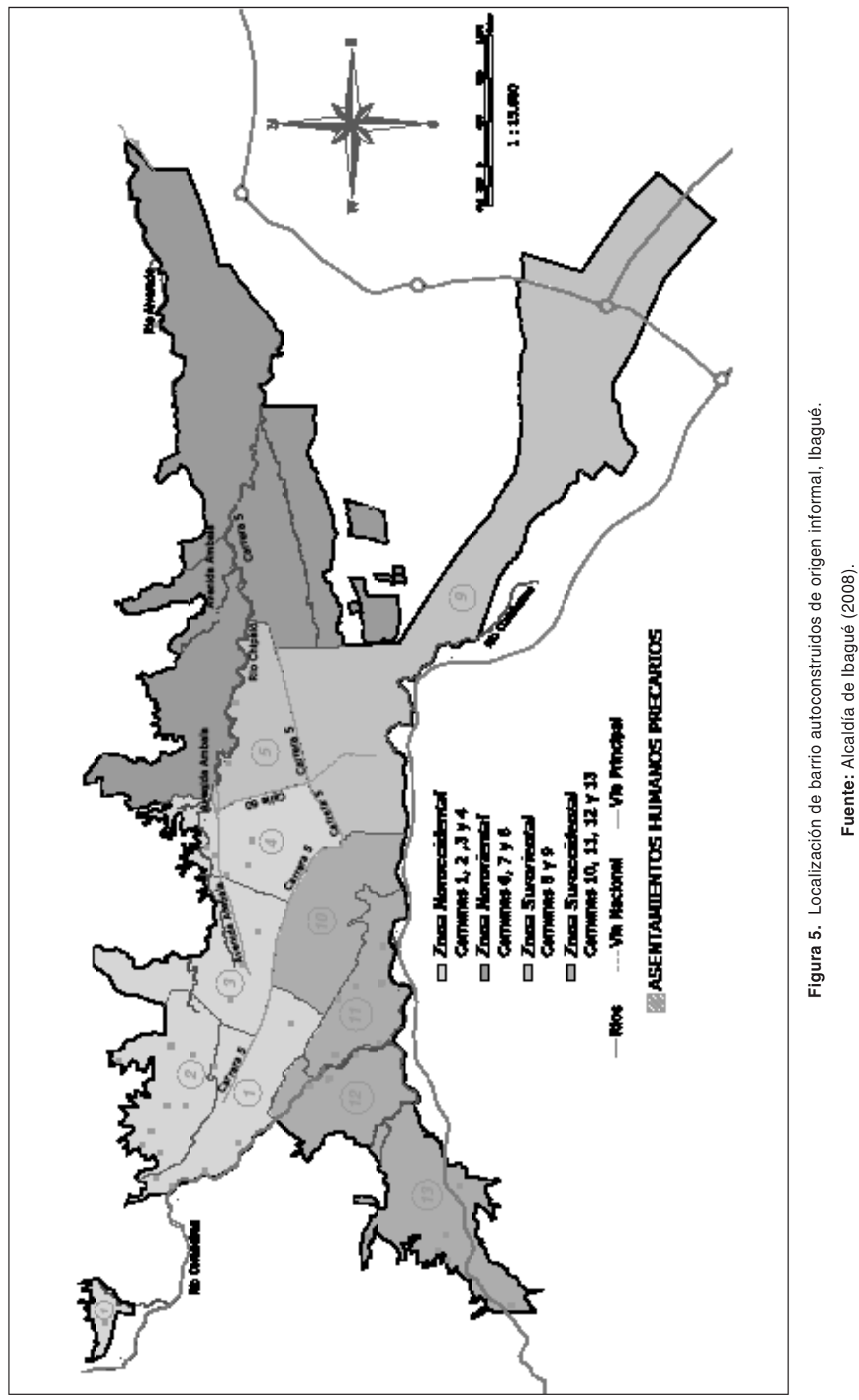


Por su parte, como islas comerciales están los centros comerciales en la conocida Milla de Oro ubicada en la calle 60, son el Centro Comercial Multicentro, Centro Comercial Acqua Power Center y el Centro Comercial La Estación (ver figura 7). Todos ellos han bajado el dinamismo comercial del centro de la ciudad tradicional, particularmente los fines de semana, pues en ellos se encuentran nuevos locales de consumo y de entretenimiento. Es así como la tendencia de una ciudad de islas como lo denomina Michael Janoshcka (2002) expresa en Ibagué una posible presencia de segregación residencial (ver figura 2), debido a: una distribución de centros comerciales y de hipermercados en el espacio urbano de manera difusa, la tendencia de construcción de conjuntos cerrados con equipamientos colectivos de uso privado y no público, la suburbanización de la industria en la periferia y al aislamiento de las construcciones de viviendas de interés social y de clase social baja hacia las zonas de expansión y periféricas de la ciudad (Janoshcka, 2002, pp. 23-24).

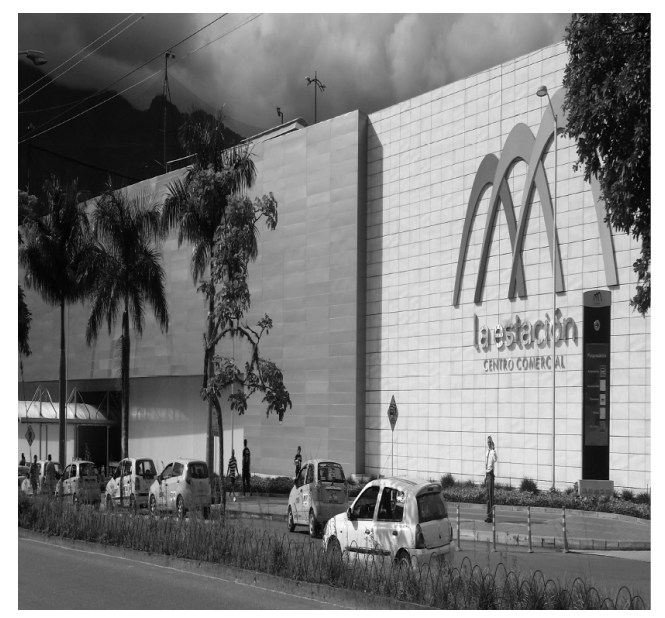

Si bien es cierto los conjuntos cerrados ya existían en la primera década del siglo xxI, su construcción se masificó promoviendo el aislamiento de los espacios urbanos y el papel del Estado en cuanto a seguridad es reemplazado por las empresas privadas. Para el caso de Ibagué no se puede afirmar que los desarrollos inmobiliarios, las zonas comerciales e industriales tengan un desarrollo fundamental a partir de un proceso de metropolización porque en Ibagué este proceso no está configurada legalmente y no hay evidencia de haberse desarrollado completamente. Sin embargo, lo que sí se podría deducir es que en Ibagué todas estas zonas se han ido distribuyendo de manera discontinua en la ciudad (ver las islas de la figura 2) en el que el centro comercial se encuentra ubicado no sólo en el centro histórico tradicional sino en nuevos "centros". En cuanto a la zona industrial se presenta la zona tradicional en decadencia frente a una zona fortalecida en la actualidad, para el caso de las zonas precarias se evidencia su carácter permanente de aislamiento y de

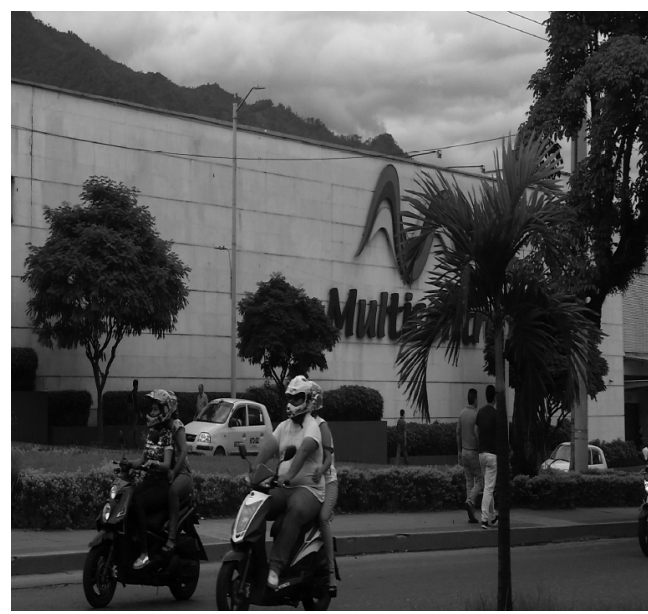

Figura 7. Centros comerciales en Ibagué.

Fuente: elaboración propia, mayo 2017 
exclusión y la percepción que se tiene de ellos como barrios marginales y peligrosos. Si bien es cierto que Ibagué no presenta un modelo igual al latinoamericano (Janoshcka, 2002) sí tiene características en común, como las mencionadas (ver figura 2).

\section{Mirada TRANSDisciplinar DE LA SEGREGACIÓN SOCIOESPACIAL}

En la ciudad se encuentra la dicotomía de centralidad y marginalidad - no en el sentido centro-periferia - de los grupos poblacionales, la cual está sujeta a una relación no simétrica entre la economía, la política y la cultura. De las dos primeras se puede decir que se contradicen entre sí en el momento de plantearse posibles agrupaciones o fusiones territoriales. Esto se debe a que los territorios políticos tienen en ellos un tiempo histórico que se lleva a cabo con las dinámicas espaciales de los actores y su cultura y no estaría bien afirmar que estos territorios puedan fusionarse de manera armoniosa con los territorios económicos, pues estos últimos son generadores de una distribución desigual del espacio, siendo esta una consecuencia de la separación de funciones económicas (Bailly, et al., 1983).

De acuerdo a lo anterior, es de suma importancia abordar transdisciplinariamente el estudio de la segregación, este fenómeno requiere integrar aspectos que analicen sus dos dimensiones - objetiva y subjetivade manera conjunta y no por separado. Es decir, desde el análisis objetivo se requiere un abordaje de orden morfológico, demográfico, económico y político, que responda al grado de concentración espacial que existe de los grupos sociales y la homogeneidad social que tienen las diferentes áreas internas de las ciudades. Por otra parte, para la dimensión subjetiva se requiere del conocimiento de aspectos importantes del territorio y de los actores sociales como la representación social; es importante en la medida en que se pueda analizar el imaginario colectivo de la segregación de acuerdo a sus representaciones, con el fin de evidenciar sus implicaciones en lo social y espacial (Alba, 2010).

No es para menos la condición necesaria y suficiente que requiere el abordaje transdisciplinario, si se tiene en cuenta por ejemplo el aporte de la geografía crítica al fenómeno, el de la antropología y el encuentro de estas dos áreas con la yuxtaposición de la identidad y el territorio, en donde la primera crea una relación de pertenencia no solo material si no también subjetiva entre el sujeto y el territorio (Giraut, 2008). No obstante, estas dos disciplinas deben estar acompañadas de la historia y la economía, la primera pondrá en evidencia los aspectos sociales y urbanos en los que ha estado inmersa la segregación de acuerdo al contexto de estudio; y la segunda, va a caracterizar al fenómeno a través de variables socioeconómicas, habitacionales y espaciales las cuales están estrechamente relacionadas con las causas principales de la segregación que son la condición socioeconómica, el mercado inmobiliario y el poder que ejerce el Estado (Lan y Linares, 2007).

Es así como el territorio se aborda de manera multidmensional en donde se tiene en cuenta el poder ejercido a través de la política y la economía y el orden cultural. Esto debido a que al territorio lo conforman áreas que son calificadas, y que producen divisiones espaciales funcionales (Bailly, et 
al., 1983; Giraut, 2008) como lo son la generación de empleo que corresponde a mano de obra barata y que esté en concordancia con la localización de la empresa donde los costos tanto laborales como operativos sean más bajos y la producción de bienes demandados y rentables, desde una perspectiva geográfica y economicista. Como consecuencia de este proceso se produce segregación no solo espacial sino también social, espacial como consecuencia de la separación de funciones en el ámbito económico que lo conforman el proceso inmediato de trabajo - fijo - y la distribución y el consumo -flujo- (Santos, 1996); y social porque favorece la posición social de los grupos poblacionales de acuerdo al capital económico y cultural que poseen, es así como los agentes son distribuidos de acuerdo a su capital y su estructura (Bozzano, 2000).

Si bien es cierto se considera la segregación como un proceso y no como un problema, la primera se debe a que las disparidades sociales tienden a ser permanentes en el tiempo pues involucra una distribución desigual de oportunidades y de beneficios en la población. Sin embargo, este proceso no es definitivo (Montaner, 2006) porque los grupos sociales se pueden ver abocados a concentrarse en grupos internamente homogéneos y disimiles; entre otros, por razones tanto económicas, sociales como culturales. La segregación socioespacial actual se presenta en barrios cerrados, en los que el espacio público queda separado del resto de la ciudad, de tal manera que el uso del mismo se reduce a una comunidad concreta, de esta manera se manifiesta una separación clara del espacio interno y del espacio externo que habitan estos grupos poblacionales, por lo que previamente las identidades de estas comunidades se encuentran encuadradas (Stavrides, 2016, p. 26).

Es relevante pensar cómo las personas han promovido a través de los imaginarios urbanos la cualificación de un lugar bien sea por sus características - peligrosos o seguros - o por ser susceptibles de intervenciones materiales, como por ejemplo las renovaciones urbanas. Estos imaginarios que se originan a partir de las representaciones que lo subyacen, son los que en el día a día contribuyen a la construcción social del espacio urbano (Lindón, 2007).

Así mismo, es importante involucrar el estudio de las representaciones sociales del espacio en la planificación urbana porque profundiza la aproximación cognoscitiva del espacio y las relaciones humanas que se desenvuelven en un territorio. Es decir, la representación social es relevante porque permite conocer la participación consciente y voluntaria que existe de una población que le permita mejorar sus condiciones de vida, de tal manera que eviten caer en el denominado "efecto vecindario". Por tal razón, la representación social del territorio se da identificándose con él a través del sentido del lugar (Alba, 2010).

Si bien es cierto, planificar una ciudad concierne a ordenar el territorio a través de la interrelación tanto física como socioeconómica y respetando el medio ambiente del mismo. Se puede considerar que esto conlleva a la intervención multidisciplinar de distintos profesionales -economistas, ambientalistas, arquitectos, entre otrosquienes a partir de sus conocimientos participan de manera conjunta en la planificación, donde el diseño "consista en adecuar los productos a las circunstancias que están 
adscritos, lo que significa sobre todo adaptarlos a las circunstancias nuevas. Un mundo que cambia, también los productos tienen que cambiar" (Aicher, 2005, p. 18).

\section{Conclusiones}

Se han planteado las características de la segregación en la escala periurbana en contextos contemporáneos (1990-2015), características que han puesto en evidencia un sistema de relaciones que se cruza con los nodos y las redes contenidas en la división territorial. A su vez, ésta es una instrumentalización del Estado, y no solo de él, también es un instrumento desde lo económico para ejercer poder, este es un primer objetivo de control (Raffestin, n.d.), con el fin de que el agente que cuenta con poder pueda transformar el entorno tanto físico como social (Raffestin, 2000). De ahí que la territorialización de las acciones de los agentes privados y públicos han transformado la expansión urbana expresada en una ciudad difusa la cual es una característica de las ciudades, independiente de su preponderancia - si son grandes o no-, demostrando así que la segregación a pesar de haber cambiado su patrón - geográficamente los grupos sociales se encuentran menos alejados - no ha dejado de ser un fenómeno que esté en aumento no por su separación física sino por su separación social.

Para el caso de Ibagué, como ciudad intermedia, se encontró que sin bien es cierto no tiene zona metropolitana definida, sí ha tenido una expansión urbana difusa, como fue referenciado, en la que se encuentran similitudes al nuevo modelo de ciudad latinoamericano planteado por Michael Janoshcka (2002) y en el que se podría decir que tanto las islas de riqueza como las islas de precariedad se han establecido en el suelo suburbano, político-administrativamente hablando.

La ciudad, al no ser un objeto si no un sistema de relaciones, es un sistema que debe ser reconsiderado y para ello se puede pensar en una ciudad imaginada en la que se construya sobre un orden social, una representación que se relacione con los grupos poblacionales que la habitan y un lenguaje que perdure en el tiempo (Raffestin, 1985). Para que así la ciudad no sea más una metáfora en relación a una ciudad que sigue la ley de la entropía tendiente al desorden (Raffestin, 1979).

\section{REFERENCIAS}

Ábramo, P. (2003). La teoría económica de la favela: cuatro notas sobre la localización residencial de los pobres y el mercado inmobiliario informal. Ciudad y Territorio: Estudios Territoriales, XXXV, 273-294.

Aicher, O. (2005). El mundo como proyecto. Barcelona, España: Gustavo Gili.

Alba, M. (2010). Representaciones sociales y el estudio del territorio: aportaciones desde el campo de la Psicología Social. En González, S. (Ed.). La integración de la dimensión espacial en las ciencias sociales y humanidades: Un proyecto docente interdisciplinario.

Alcaldía de Ibagué. (2008). Estudio de caracterización e identificación de asentamientos humanos precarios en la ciudad de Ibagué. Ibagué, Colombia.

Aprile, J. y Mosquera, G. (1984). Clases, Segregación y Barrios. Cali, Colombia: Universidad del Valle.

Ayala, J. (2014). Crecimiento económico y empleo en Ibagué. Documentos de Trabajo Sobre Economía Regional. 
Bäbr, J. y Borsdorf, A. (2005). La Ciudad Latinoamericana: La construcción de un modelo. Vigencia y perspectivas. Revista de Ciudad, Urbanismo y Paisaje Ur[b] Es, 207-221.

Bailly, A. S.; Aydalot, P.; Godbout, J.; Hussy, C.; Raffestin, C. et Turco, A. (1983). La marginalité: réflexions conceptuelles et perspectives en géographie, sociologie et économie. Géotopiques, 1, 73-115. En ligne. Trouvé dans: http://archive-ouverte. unige.ch/unige:4332/ATTACHMENT01

Bernardes da Silva, A. y Castillo, R. (2007). Dinámicas metropolitanas en la era de la globalización: la promoción inmobiliaria para empresas en la ciudad de São Paulo, Brasil. EURE (Santiago), XXXIII (98), 45-56. En línea. Recuperado de: https://doi.org/10.4067/ S0250-71612007000100003

Bozzano, H. (2000). Territorios Reales, Territorios Pensados, Territorios Posibles. Aportes para una Teoría Territorial del Ambiente. Buenos Aires, Argentina: Espacio Editorial.

Capel, H. (2002). Redes, Chabolas y Rascacielos. Las Transformaciones físicas y la planificación en las áreas metropolitanas. Seminario Internacional sobre "El desafío de las áreas metropolitanas en un mundo globalizado. Una mirada a Europa y América Latina". Barcelona, España: Institut d'Estudis Territorials de la Universitat Pompeu Fabra.

Ciccolella, P. y Vecslir, L. (2010). Nuevos espacios del terciario y transformación metropolitana en Buenos Aires. XI Seminario Internacional RII y IV Taller de Editores RIER Universidad Nacional de Cuyo. Universidad Nacional de Cuyo.

Consejo Municipal de Ibagué. (2014). Decreto No. 1000-0823 de 2014. Plan de Ordenamiento Territorial. Ibagué.
Corrêa, R. L. (1989). O Espaço Urbano. São Paulo, Brasil: Ática S.A.

Cortés, J. M. (2010). La ciudad cautiva. Control y vigilancia en el espacio urbano. Madrid, Espña: Akal S.A.

Cuervo, L. M. (2010). América Latina : metrópolis en mutación. XI Seminario Internacional de la Red de Investigadores en Globalización y Territorio (RII). Mendoza.

De Mattos, C. A. (2001). Metropolización y suburbanización. EURE, XXVII (80).

De Mattos, C. A. (2002). Santiago de Chile de cara a la Globalización: ¿otra ciudad? Revista de Sociologia e Política, 19, 31-54. En línea. Recuperado de: https://doi. org/http://dx.doi.org/10.5380/rsp.v19i0

De Mattos, C. A. (2012). Notas sobre una falsa disyuntiva: redensificación de las áreas centrales versus dispersión urbana. Tendencias recientes, evidencia empírica. Instituto de Estudios Urbanos y territoriales.

Dematteis, G. y Governa, F. (2005). Territorio $\mathrm{Y}$ Territorialidad En El Desarrollo Local. Boletín de La A. G. E, 39, 31-58.

Espinosa, M. A. (1992). Crecimiento Urbano de Ibagué 1938-1989. Universidad Pedagógica y Tecnológica de Colombia.

Fernández, R. (1996). La Explosión del Desorden. La Metrópoli como Espacio de la Crisis Global. Madrid: Editorial Fundamentos.

Fraser, N. (2008). Escalas de Justicia. Barcelona, España: Herder Editorial, S. L., Barcelona.

Giraut, F. (2008). Conceptualiser le territoire. Historiens et Géographes, 403, 57-68.

González, J. (2006). De la ciudad al territorio. La configuración del espacio urbano en Ibagué 1886-1986. Ibagué, Colombia: Aquelarre. Centro Cultural Universidad del Tolima. Harvey, D. (1977). Urbanismo y Desigualdad Social. Madrid: Siglo Veintiuno Editores, S.A. 
Harvey, D. (2013). Ciudades rebeldes: Del derecho de la ciudad a la revolución urbana. Madrid: Akal S.A.

Harvey, D. y Smith, N. (2005). Capital financiero, propiedad inmobiliaria y cultura. Barcelona, España: Universitat Autonoma de Barcelona.

Hiernaux, D. (1999). Los frutos amargos de la globalización: expansión y reestructuración metropolitana de la ciudad de México. EURE (Santiago), 25 (76), 1-14. En línea. Recuperado de: https://doi. org/10.4067/S0250-71611999007600003

Janoshcka, M. (2002). El nuevo modelo de la ciudad Latinoamericana: Fragmentación y privatiación. EURE, XXVIII, 11-29. En línea. Recuperado de: https://doi.org/http://dx.doi.org/10.4067/ S0250-71612002008500002

Janoshcka, M. y Glasze, G. (2003). Urbanizaciones cerradas: un modelo analítico. CIUDADES. Puebla.

Lacarrieu, M. (2007). La "insoportable levedad" de lo urbano. Eure, 33(99), 47-64. En línea. Recuperado de: https://doi. org/10.4067/S0250-71612007000200005

Lan, D. y Linares, S. (2007). Análisis Multidimensional De La Segregación Socioespacial en Tandil (Argentina) Aplicando SIG. Investigaciones Geográficas, 44, 149-166.

Lindón, A. (2007). Los imaginarios urbanos y el constructivismo geográfico: Los hologramas espaciales. Eure, 33(99), 31-46. En línea. Recuperado de: https://doi. org/10.4067/S0250-71612007000200004

López, A. (2017). Segregación Residencial en el municipio de Ibagué, departamento del Tolima, Colombia. 1990 - 2017. Un abordaje Territorial Multidimensional [Mimeo]. Ibagué, Colombia.

Méndez, R. (2001). Transformaciones económicas y reorganización territorial en la región metropolitana de Madrid. EURE, XXVII, 141-161.

Montaner, J. (2006). Vulnerabilidades urbanas: separar, olvidar, deshabitar. Las otras geografias. Valencia, España: Tirant Lo Blanch.

Moura, R. (2003). Inversiones urbanas en el contexto de la competitividad y globalización: los eventos en Curitiba. EURE (Santiago), 29 (86), 51-68. En línea. Recuperado de: https://doi.org/10.4067/ S0250-71612003008600003

Nates, B. (2011). Soportes teóricos y etnográficos sobre conceptos de territorio. Co-Herencia, 8(14), 209-229.

Nel.lo, O. (1998). Los confines de la ciudad sin confines. Estructura urbana y límites administrativos en la ciudad difusa. En Monclús, J. (Ed.), La ciudad dispersa. Centre de Cultura Contemporánia de Barcelona.

Pereira, P. C. X. (2004). Reestruturação e Expansão Metropolitana: a reestruturação imobiliária e a emergência de um novo modelo de metrópole na América Latina . VIII Seminário Internacional de la Red de Investigadores sobre Globalización. Río de Janeiro, Brasil.

Prévôt, M.-F. (2000). Segregación, fragmentación, secesión. Hacia una nueva geografía social en la aglomeración de Buenos Aires. Economía, Sociedad y Territorio, II (7), 405-431.

Programa Ibagué Cómo Vamos. (2015). Informe de calidad de vida de Ibagué. Ibagué.

Raffestin, C. (s.d.). La pratique politique et le découpage territorial.

Raffestin, C. (1979). La ville comme métaphore. Médecine E Hygiène, 37 (1352), 3749-3750.

Raffestin, C. (1985). A propos de l'imagination géographique ou réflexions dans les 
marges pour tenter de penser le centre. Géotopiques: L'imagination Géographique Les Niveaux Indicateur Territoriaux, La Marginalité, l'économie Submergée, 5-7.

Raffestin, C. (2000). Les projets de fusion territoriale: entre politique et économie. Bulletin de La Société NeuchâTeloise de Géographie, 44, 9-18. En ligne. Trouvé dans: http://archive-ouverte.unige. ch/unige:4394\%5Cnhttp://archive-ouverte.unige.ch/download/unige:4394/ ATTACHMENT01

Ríos, M. (2010). Segregación Residencial; el Problema Social Desde la Perspectiva Económica y Urbana. Universidad $\mathrm{Na}$ cional de Colombia. Bogotá, Colombia.

Rivera, J. A. (2013). Proceso de urbanización y agentes urbanos Directores: Horacio Capel Sáez Territorial y Gestión Ambiental Universidad de Barcelona Facultat de Geografia $i$ Historia. Universidad de Barcelona.

Sabatini, F. y Cáceres, G. (2005). Relación entre Promoción Inmobiliaria y Segregación Residencial: Giros Insospechados de la Ciudad Latinoaméricana. Lincoln Institute of Land Policy. En línea. Recuperado de: https://doi.org/10.1017/ CBO9781107415324.004

Sabatini, F., Cáceres, G., yCerda, J. (2001). Segregación residencial en las principales ciudades chilenas: Tendencias de las tres últimas décadas y posibles cursos de acción. EURE, XXVII. En línea. Recuperado de: https://doi.org/http://dx.doi. org/10.4067/S0250-71612001008200002

Santos, M. (1996). Metamorfosis del espacio habitado. Barcelona, España: Oikus-Tau S.L. En línea. Recuperado de: https:// doi.org/B-41.934-1996
Sassen, S. (2007). El reposicionamiento de las ciudades y regiones urbanas en una economía global: Ampliando las opciones de políiticas y gobernanza. Eure, 33 (100), 9-34. En línea. Recuperado de: https://doi.org/10.4067/S0250 $-71612007000300002$

Sassen, S. (2015). Expulsiones. Brutalidad y Complejidad en la Economía Global. Buenos Aires, Argentina: Katz Editores.

Schteingart, M. (2001). La división social del espacio en las ciudades. Perfiles Latinoamericanos, 13-31.

Stavrides, S. (2016). Hacia la Ciudad de Umbrales. Madrid: Ediciones Akal S.A.

Torres, C. A.; Gaviria, A.; Zuñiga, D.; Vargas, J.; Nieto, D. y Bustos, S. (2009). Ciudad informal colombiana Barrios construidos por la gente. Universidad Nacional de Colombia.

Valdés, E. (2007). Fragmentación y segregación urbana. Aportes teóricos para el análisis de casos en la ciudad de Córdoba. Alfilo. Revista digital de la Facultad de Filosofía y Humanidades. En línea. Recuperado de: http://sistemamid.com/panel/uploads/ biblioteca/7097/7128/7129/83441.pdf

Vargas D, I.; Jiménez M, E.; Grindlay M, A. y Torres T, C. (2010). Procesos de Mejoramiento Barrial Participativo en Asentamientos Informales: Propuestas de Integración en la Ciudad de Ibagué (Colombia). Revista Invi, 25 (68), 59-96. En línea. Recuperado de: https://doi.org/http://dx.doi.org/10.4067/ S0718-83582010000100003

Vega-Centeno, P. (2017). La dimensión urbana de las centralidades de Lima Norte : cambios y permanencias en la estructura metropolitana. EURE, 43 (129), 5-25. 